\title{
Ultrasound-Assisted Extraction of Bioactive Compounds from Annatto Seeds, Evaluation of Their Antimicrobial and Antioxidant Activity, and Identification of Main Compounds by LC/ESI-MS Analysis
}

\author{
Julian Quintero Quiroz ${ }^{1},{ }^{1}$ Ana Maria Naranjo Duran, ${ }^{1}$ Mariluz Silva Garcia, ${ }^{2}$ \\ Gelmy Luz Ciro Gomez, ${ }^{1}$ and John Jairo Rojas Camargo ${ }^{1}$ \\ ${ }^{1}$ College of Pharmaceutical and Food Sciences, University of Antioquia, Street 67, No. 53-108, Medellin, Colombia \\ ${ }^{2}$ Institute of Food Science and Technology (INTAL), Carrera $50 \mathrm{~g}$ No. 12S-91, Itagüi, Colombia
}

Correspondence should be addressed to Julian Quintero Quiroz; julian.quintero@udea.edu.co

Received 18 January 2019; Accepted 15 June 2019; Published 16 July 2019

Academic Editor: Mitsuru Yoshida

Copyright (C) 2019 Julian Quintero Quiroz et al. This is an open access article distributed under the Creative Commons Attribution License, which permits unrestricted use, distribution, and reproduction in any medium, provided the original work is properly cited.

\begin{abstract}
This study evaluated the antimicrobial activity (i.e., against Bacillus cereus and Staphylococcus aureus) and the antioxidant activity (i.e., ABTS, FRAP, and DPPH) of annatto seeds extract obtained by ultrasound-assisted extraction. A response surface design with three levels such as $\mathrm{pH}$ (2-11), solvent concentration (50-96\%), seed-to-solvent ratio (1:2-1:10), and treatment time (0-30 min) was employed to determine the optimal experimental conditions. Thus, a $\mathrm{pH}$ of 7.0, seed-to-solvent ratio of $1: 7$, and treatment time of $20 \mathrm{~min}$ were selected as optimal rendering an extract having a $0.62 \%$ of bixin, $3.81 \mathrm{mg}$ gallic acid/mg equivalent of polyphenol compounds (ABTS 1035.7, FRAP 424.7, and DPPH $1161.5 \mu \mathrm{M}$ trolox/L), and a minimal inhibitory concentration against Bacillus cereus and Staphylococcus aureus of 32 and $16 \mathrm{mg} / \mathrm{L}$, respectively. Further, the main bioactive compounds identified by LC/ESI-MS were bixin and catechin, chlorogenic acid, chrysin, butein, hypolaetin, licochalcone A, and xanthohumol.
\end{abstract}

\section{Introduction}

The seeds of annatto (Bixa orellana $L$.) are widely employed as a dye for foods such as butter, cheese, soft drinks, and confectionery. The pigment obtained from this plant is rich in carotenoids (i.e., bixin) and polyphenol compounds such as hypolatin and caffeic acid [1]. The antioxidant ability of the extract is attributed to the high conjugation of these compounds and their ability to quench singlet oxygen, deactivation of the excited triplet state of sensitizers usually associated with photosensitization, sweeping free radicals, and denaturation of proteins from cell membranes. Further, the extract exhibits anti-inflammatory, antioxidant, and antimicrobial activities [2]. However, the extraction method affects the functional properties of the extract. Traditionally, different extraction methods for bioactive compounds include percolation, solvent extraction or leaching, enzyme-assisted extraction, and liquid-liquid microextraction [3]. However, conventional methods, such as solvent extraction or leaching, require a long processing time, exposing the bioactive compounds to degradation factors leading to a low efficiency [4].

To date, ultrasound and microwaves-assisted extractions have been reported for the extraction of several components. Particularly, mechanical methods, spouted bed, ultrasound-assisted extraction, microwave-assisted extraction, and supercritical fluids $\left(\mathrm{CO}_{2}\right)$ have been employed for annatto seed extraction [3, 5-7]. Nonetheless, these studies have been focused exclusively on the extraction of the pigment, leaving aside the evaluation of the effect of the extraction treatment on activities such as antimicrobial and antioxidant. The increase of the extraction yield of the bioactive compounds obtained by the ultrasound and microwaveassisted techniques is attributed to the acceleration of mass 
transfer from the solid-phase to the liquid-phase [3]. The ultrasound-assisted extraction (UAE) creates cavitation of small bubbles in the solvent due to the passage of ultrasound waves allowing for a greater penetration of the solvent within the material increasing the surface area. On the other hand, microwave-assisted extraction implies the formation of high-energy electromagnetic waves changing the molecular rotation and ionic mobility of the medium without destroying the sample, resulting in heating and possibly denaturation of bioactive compounds. The last two methods force the migration of all active compounds rapidly from the solidphase to the solvent-phase. However, the UAE shows a better protection of those compounds due to the lower temperature generated in the medium $[8,9]$.

Further, not only the evaluation of the functional activity of the extracts, but also the identification of the compounds responsible for that activity is crucial. In general, bixin, phenolic acids, lignans, and flavonoids are the main bioactive compounds. However, the isolation and identification of these compounds require techniques having a high separation efficiency since coeluting compounds could be missed [10]. Currently, HPLC coupled with mass spectrometry at atmospheric pressure chemical ionization (APCI) or electrospray ionization (ESI) represents the most selective analytical technique for the identification and quantification of compounds isolated from plants and food sources. The identification of carotenoids and polyphenol compounds by LC-ESI-MS using a LTQ Orbitrap XL renders an extremely high mass accuracy ( $<5 \mathrm{ppm}$ of resolution). This technique is capable of multiple levels of fragmentation to reveal the molecular weight (MW) of unknown compounds. Hence, by using this technique, unknown compounds are identified on the basis of nominal MW and MS/MS fragmentation [10].

The goal of this study was to enhance the extraction of bioactive compounds from the seeds of annatto and optimize the extraction conditions (i.e., solvent concentration, $\mathrm{pH}$, treatment time, and seed-to-solvent ratio) as compared to a conventional method. Further, it is expected that the antimicrobial and antioxidant activity is due to the high yield of extracted compounds as identified by LC/ESI-MS.

\section{Materials and Methods}

2.1. Materials. Annatto seeds were purchased from a farmers market of Medellín (Colombia), which were sun-dried until reaching a moisture content of $10.58 \pm 0.98 \%$. All the reagents used were synthesis grade.

2.2. Experimental Design. The UAE conditions were optimized using a response surface plot experimental design (Box-Behnken (BBD)), using the Design Expert Software ${ }^{\circledR}$ (Version 8.0.6, Stat-Ease, USA). The dependent variables such as treatment time $(\mathrm{min})\left(\mathrm{X}_{1}, 0-30\right), \mathrm{pH}\left(\mathrm{X}_{2}, 4-11\right)$, solvent concentration (\%) $\left(\mathrm{X}_{3}: 50-96\right)$, and seed-to-solvent ratio $\left(\mathrm{X}_{4}\right.$, 2-10) were studied. The solvent used was absolute ethanol (lot k4958171742, Merck Darmstadt, Germany). With the independent variables studied, the statistical program established 30 experimental units, which are presented in Table 1 with their respective randomization. The two independent variables studied were the bixin content (Bix) and the total polyphenol content found by the Folin-Ciocalteu method, using a uv/vis spectrophotometer (UV-1700, Shimadzu) [11].

The operational conditions of the equipment used for the UAE were a frequency of $37 \mathrm{KHz}$ and a power of $320 \mathrm{~W}$ (Elmasonic E30h). Adjustment of the $\mathrm{pH}$ was done with $0.1 \mathrm{M}$ acetic acid (lot k47109963539, Merck Darmstadt, Germany) and 0.1 M sodium hydroxide solution (lot b0895598319, Merck Darmstadt, Germany). The method of multiple regressions of least squares was used in order to optimize the extraction conditions and investigate the effect of the independent variables. The experimental data was adjusted by the secondorder polynomial equation (see (1)) by comparison of the determination coefficient $\left(\mathrm{r}^{2}\right)$ and the adjusted determination coefficient $\left(\mathrm{r}^{2}\right.$-adj). The quadratic model follows the expression

$$
\begin{aligned}
\mathrm{Y}= & \beta_{0}+\beta_{1} \mathrm{X}_{1}+\beta_{2} \mathrm{X}_{2}+\beta_{3} \mathrm{X}_{3}+\beta_{4} \mathrm{X}_{4}+\beta_{11} \mathrm{X}_{11} \\
& +\beta_{22} \mathrm{X}_{2}^{2}+\beta_{33} \mathrm{X}_{3}^{2}+\beta_{44} \mathrm{X}_{4}^{2}+\beta_{12} \mathrm{X}_{1} \mathrm{X}_{2}+\beta_{13} \mathrm{X}_{1} \mathrm{X}_{3} \\
& +\beta_{14} \mathrm{X}_{1} \mathrm{X}_{4}+\beta_{23} \mathrm{X}_{2} \mathrm{X}_{3}+\beta_{24} \mathrm{X}_{2} \mathrm{X}_{4}+\beta_{34} \mathrm{X}_{3} \mathrm{X}_{4}
\end{aligned}
$$

where $\mathrm{Y}$ represents the predicted response, $\beta_{0}$ is the intercept of the model, $\beta_{1}, \beta_{2}, \beta_{3}, \beta_{4}, \beta_{11}, \beta_{22}, \beta_{33}, \beta_{44} \mathrm{y} \beta_{12}, \beta_{13}, \beta_{14}$, $\beta_{23}, \beta_{24}$, and, $\beta_{34}$ are the linear and interaction coefficients, respectively, and $\mathrm{X}_{1}, \mathrm{X}_{2}, \mathrm{X}_{3}$, and, $\mathrm{X}_{4}$ correspond to the independent variables. Analysis of variance (ANOVA) was used to analyze the significant effects (with a confidence level of 95\%) of the independent variables over the dependent variables. Once the significant mathematical models were obtained, the extraction process was optimized, seeking to maximize the extraction of polyphenols and bixin (weight of 1 for both) and minimizing the seed-to-solvent ratio. The calculation of the relative and absolute errors was accomplished between the responses predicted by the model versus the ones obtained experimentally under optimal conditions.

2.3. Characterization of Optimized Annatto Seed Extracts. The antioxidant and antimicrobial activities of the optimized extracts obtained by the UAE were compared with (i) an extract obtained by conventional extraction (with ethanol, seeds-to-solvent ratio of 1:2, and continuous agitation for 48 h) and (ii) previous results from an optimized microwaveassisted extraction [12]. The results are presented as means and standard deviation (SD). The analysis was performed using the Statgraphics ${ }^{\circledR}$ Centurion XVI software.

2.4. Quantification of Total Polyphenol. The total phenolic concentration in the annatto seed extract was measured by the Folin-Ciocalteu method [13]. Twenty microliter of sample was mixed with in $1.58 \mu \mathrm{L}$ of distilled water, $100 \mu \mathrm{L}$ of FolinCiocalteu phenol reagent (lot hc43368401, Merck Darmstadt, Germany) and $300 \mu \mathrm{L}$ of $20 \%$ sodium carbonate (lot a0594092339, Merck Darmstadt, Germany). The absorbance was read at $725 \mathrm{~nm}$ in a UV/VIS spectrophotometer (UV1700, Shimadzu) after 1 h of storage under darkness. The experiments were performed in triplicate and the results were expressed as mg of gallic acid (GA) (lot SLBM8746V, Merck Darmstadt, Germany) per gram of seeds (mgGA/g seed). 
TABLE 1: The experimental matrix for the UAE of bioactive compounds from annatto seeds.

\begin{tabular}{|c|c|c|c|c|c|c|c|c|c|c|}
\hline \multirow{2}{*}{$\begin{array}{l}\text { Treatment } \\
\text { number }\end{array}$} & \multirow{2}{*}{$\begin{array}{c}\begin{array}{c}\text { UAE } \\
\text { Treatment } \\
\text { time } \\
(\min )\end{array} \\
0.00\end{array}$} & \multirow{2}{*}{$\begin{array}{c}\mathrm{pH} \\
7.50\end{array}$} & \multirow{2}{*}{$\begin{array}{c}\begin{array}{c}\text { Solvent } \\
\text { Concentration } \\
(\%)\end{array} \\
73.00\end{array}$} & \multirow{2}{*}{$\begin{array}{c}\begin{array}{c}\text { Seed-to } \\
\text { solvent ratio } \\
\left(1: \mathrm{X}_{4}\right)\end{array} \\
10.00\end{array}$} & \multicolumn{6}{|c|}{ UAE } \\
\hline & & & & & 1.57 & \pm & 0.094 & 0.17 & \pm & 0.053 \\
\hline 2 & 15.00 & 4.00 & 50.00 & 6.00 & 1.50 & \pm & 0.014 & 0.15 & \pm & 0.038 \\
\hline 3 & 15.00 & 7.50 & 50.00 & 10.00 & 1.92 & \pm & 0.017 & 0.32 & \pm & 0.030 \\
\hline 4 & 15.00 & 4.00 & 96.00 & 6.00 & 2.15 & \pm & 0.135 & 0.54 & \pm & 0.049 \\
\hline 5 & 15.00 & 7.50 & 73.00 & 6.00 & 2.06 & \pm & 0.068 & 0.31 & \pm & 0.029 \\
\hline 6 & 0.00 & 11.00 & 73.00 & 6.00 & 1.90 & \pm & 0.155 & 0.38 & \pm & 0.035 \\
\hline 7 & 30.00 & 11.00 & 73.00 & 6.00 & 1.80 & \pm & 0.023 & 0.67 & \pm & 0.066 \\
\hline 8 & 15.00 & 11.00 & 96.00 & 6.00 & 2.17 & \pm & 0.032 & 0.57 & \pm & 0.068 \\
\hline 9 & 0.00 & 7.50 & 50.00 & 6.00 & 1.59 & \pm & 0.119 & 0.17 & \pm & 0.013 \\
\hline 10 & 15.00 & 7.50 & 50.00 & 2.00 & 1.11 & \pm & 0.137 & 0.12 & \pm & 0.086 \\
\hline 11 & 30.00 & 4.00 & 73.00 & 6.00 & 2.03 & \pm & 0.056 & 0.39 & \pm & 0.018 \\
\hline 12 & 15.00 & 4.00 & 73.00 & 2.00 & 1.11 & \pm & 0.029 & 0.39 & \pm & 0.019 \\
\hline 13 & 15.00 & 7.50 & 73.00 & 6.00 & 1.86 & \pm & 0.073 & 0.31 & \pm & 0.019 \\
\hline 14 & 30.00 & 7.50 & 96.00 & 6.00 & 2.05 & \pm & 0.157 & 0.50 & \pm & 0.030 \\
\hline 15 & 15.00 & 11.00 & 73.00 & 10.00 & 2.49 & \pm & 0.154 & 0.20 & \pm & 0.025 \\
\hline 16 & 15.00 & 11.00 & 50.00 & 6.00 & 1.57 & \pm & 0.065 & 0.19 & \pm & 0.004 \\
\hline 17 & 0.00 & 7.50 & 96.00 & 6.00 & 1.76 & \pm & 0.134 & 0.22 & \pm & 0.016 \\
\hline 18 & 15.00 & 7.50 & 96.00 & 2.00 & 1.53 & \pm & 0.099 & 0.54 & \pm & 0.008 \\
\hline 19 & 15.00 & 7.50 & 73.00 & 6.00 & 2.11 & \pm & 0.143 & 0.33 & \pm & 0.012 \\
\hline 20 & 15.00 & 7.50 & 96.00 & 10.00 & 2.85 & \pm & 0.066 & 0.64 & \pm & 0.031 \\
\hline 21 & 30.00 & 7.50 & 73.00 & 2.00 & 1.50 & \pm & 0.132 & 0.39 & \pm & 0.029 \\
\hline 22 & 15.00 & 7.50 & 73.00 & 6.00 & 1.85 & \pm & 0.246 & 0.27 & \pm & 0.058 \\
\hline 23 & 15.00 & 11.00 & 73.00 & 2.00 & 1.57 & \pm & 0.180 & 0.47 & \pm & 0.022 \\
\hline 24 & 30.00 & 7.50 & 73.00 & 10.00 & 2.72 & \pm & 0.140 & 0.38 & \pm & 0.025 \\
\hline 25 & 0.00 & 4.00 & 73.00 & 6.00 & 1.42 & \pm & 0.113 & 0.24 & \pm & 0.037 \\
\hline 26 & 15.00 & 7.50 & 73.00 & 6.00 & 2.16 & \pm & 0.121 & 0.33 & \pm & 0.017 \\
\hline 27 & 30.00 & 7.50 & 50.00 & 6.00 & 1.33 & \pm & 0.098 & 0.27 & \pm & 0.014 \\
\hline 28 & 0.00 & 7.50 & 73.00 & 2.00 & 1.47 & \pm & 0.064 & 0.38 & \pm & 0.041 \\
\hline 29 & 15.00 & 4.00 & 73.00 & 10.00 & 2.33 & \pm & 0.094 & 0.28 & \pm & 0.007 \\
\hline 30 & 15.00 & 7.50 & 73.00 & 6.00 & 2.03 & \pm & 0.014 & 0.35 & \pm & 0.047 \\
\hline
\end{tabular}

Values are expressed as mean \pm standard deviation $(n=3)$. UAE: ultrasound-assisted extraction; AG: gallic acid.

2.4.1. Quantification of Bixin. $100 \mu \mathrm{L}$ of sample with $2 \mathrm{~mL}$ of tetrahydrofuran (lot dg643, Merck Darmstadt, Germany) and $10 \mathrm{~mL}$ of acetone (lot k43912814243, Merck Darmstadt, Germany) were mixed to obtain an absorbance of less than 0.15 at $487 \mathrm{~nm}$ taken in a UV/VIS spectrophotometer (UV1700, Shimadzu). The concentration of bixin in the sample was determined using the following equation [14]:

$$
\operatorname{Bixin}(m g / m L)=\frac{A * 100 * V}{A_{1 c m}^{1 \%} * 100}
$$

where

$A_{1 \mathrm{~cm}}^{1 \%}=3090(1 \mathrm{~g} / 100 \mathrm{~mL})^{-1} * 1 \mathrm{~cm}^{-1}$ (specific absorptivity coefficient of bixin in acetone) [14];

$\mathrm{A}=$ absorbance value of the sample;

$\mathrm{V}=$ dilution volume of the sample $(\mathrm{mL})$.
2.4.2. Antioxidant Activity, ABTS ${ }^{+}$Method. The ABTS assay was performed following the method described by Contreras et al. 2011 [15]. One hundred microliter of sample (diluted appropriately with water) was mixed with $1 \mathrm{~mL}$ of $\mathrm{ABTS}^{+}$ solution, which was prepared with ABTS standard $\left(2,2^{\prime}\right.$ Azino-bis(3-ethylbenzothiazoline-6-sulfonic acid) diammonium salt, lot slbp9592v, sigma-Aldrich, St. Lois, USA) diluted in ethanol. The change in coloration was read after $30 \mathrm{~min}$ at $730 \mathrm{~nm}$ in a spectrophotometer (UV-1700, Shimadzu). The results were expressed as trolox equivalents (TE) (6-hydroxy2,5,7,8-tetramethylchromane-2-carboxylic acid to 97\%, lot stbb6668, sigma-Aldrich, St. Lois, USA) or TE $\mu \mathrm{mol} / \mathrm{L}$.

2.4.3. Antioxidant Activity, Ferric Reducing Antioxidant Power (FRAP) Method. The FRAP was measured according to 
Benzie and Strain (1996) with modifications [16]. Briefly, 30 $\mu \mathrm{L}$ of sample, $90 \mu \mathrm{L}$ of deionized water (diluted appropriately with water), and $900 \mu \mathrm{L}$ of the FRAP reagent (prewarmed at $37^{\circ} \mathrm{C}$ ) were mixed. The sample was incubated for 30 minutes at $37^{\circ} \mathrm{C}$. Then, the change in coloration was read at $593 \mathrm{~nm}$ in a spectrophotometer (UV-1700, Shimadzu). A Trolox (6hydroxy-2,5,7,8-tetramethylchromane-2-carboxylic acid to 97\%, lot stbb6668, sigma-Aldrich, St. Lois, USA) calibration curve was obtained for quantification purposes and the results were expressed as TE $\mu \mathrm{mol} / \mathrm{L}$.

2.4.4. Antioxidant Activity, DPPH Method. The DPPH assay was performed as previously described [17]. Briefly, $2 \mathrm{~mL}$ of $0.5 \mathrm{mM}$ 2,2-diphenyl-1-picrylhydrazyl or DPPH (067k lot 1154, sigma-Aldrich, St. Lois, USA) reagent was mixed with $2 \mathrm{~mL}$ of methanol (lot 1823009611, Merck Darmstadt, Germany) and $0.2 \mathrm{~mL}$ of sample (diluted appropriately with water). The change in coloration was read after 30 min of incubation in darkness at $517 \mathrm{~nm}$ in a spectrophotometer (UV-1700, Shimadzu). A Trolox (6-hydroxy-2,5,7,8tetramethylchromane-2-carboxylic acid to $97 \%$, lot stbb6668, sigma-Aldrich, St. Lois, USA) calibration curve was obtained for quantification purposes and the results were expressed as $\mathrm{TE} \mu \mathrm{mol} / \mathrm{L}$.

2.4.5. Minimal Inhibitory Concentration of Annatto Seed Extracts. The antibacterial activity was evaluated against Bacillus cereus (ATCC 11778) and Staphylococcus aureus (ATCC 6538). Bacterial strains were incubated for $24 \mathrm{~h}$ at $37^{\circ} \mathrm{C}$ in a Mueller-Hinton broth (lot b1223098542, Merck Darmstadt, Germany) and adjusted to a McFarland scale 0.5 $\left(10^{6} \mathrm{CFU} / \mathrm{mL}\right)$. Samples were dissolved in dimethylsulfoxide (DMSO) (lot 190260, Merck Darmstadt, Germany) to reach concentrations ranging from 4 to $4096 \mathrm{mg} / \mathrm{L}$. Ninety-six well microplates were prepared by adding $20 \mu \mathrm{L}$ of sample, 120 $\mu \mathrm{L}$ of Mueller-Hinton broth, and $10 \mu \mathrm{L}$ of inoculum. The positive and negatives controls were prepared according to previous reports [12]. After incubation for $5 \mathrm{~h}$ at $37^{\circ} \mathrm{C}, 25$ $\mu \mathrm{L}$ of 3-(4,5-dimethylthiazol-2-yl)-2,5-diphenyl-tetrazolium bromide (MTT) (lot p31b064, Alfa Aesar, Tewksbury, USA) was added to each well and incubated for $1 \mathrm{~h}$. The minimum inhibitory concentration (MIC) was considered as the concentration of the first well that did not suffer from any color change (from yellow to purple). The procedure was repeated three times for each microorganism and $\mathrm{pH}(4,7$, and 11) [2].

2.5. Identification of Bioactive Compounds (Polyphenols and Bixin) by LC/ESI-MS Analysis. The extract obtained at the optimal operational conditions by UAE was analyzed for the identification of the bioactive compounds. LC/ESI-MS analyses were performed using an UHPLC (Thermo Fisher Scientific Ultimate 3000) coupled with an orbitrap Q-exactive mass spectrometer (Thermo Fisher Scientific, Waltham, MA, USA). Chromatographic separation was done by reversphase elution equipped with a SiliaChrom ${ }^{\circledR}$ Plus C18 (SILICYCLE) HPLC column ( $4.6 \times 150 \mathrm{~mm}, 5 \mu \mathrm{m}, 100 \AA)$. The mobile phase consisted of a combination of A $(0.1 \%$ formic acid (lot 798381, PanReac AppliChem, Barcelona, Spain) in water) and B (0.1\% formic acid in acetonitrile (lot 830491, PanReac
TABLE 2: ANOVA table for the response variables for the UAE of bioactive compounds from annatto seeds.

\begin{tabular}{lcc}
\hline Variable & \multicolumn{2}{c}{ UAE } \\
& $\begin{array}{c}\text { Polyphenol } \\
\text { (mg AG/g seed }) \\
\text { p-value }\end{array}$ & Bixin (\%) \\
\hline Model & $<0.0001$ & $<0.0001$ \\
$\mathrm{X}_{1}$-Treatment time (min) & $>0.050$ & 0.006 \\
$\mathrm{X}_{2}$-pH & $>0.050$ & 0.065 \\
$\mathrm{X}_{3}$ - Solvent concentration $(\%)$ & 0.0001 & $<0.0001$ \\
$\mathrm{X}_{4}$ - Seed-to-solvent ratio $\left(1: \mathrm{X}_{4}\right)$ & $<0.0001$ & 0.003 \\
$\mathrm{X}_{3} \mathrm{X}_{4}$ & $>0.050$ & $<0.0001$ \\
$\mathrm{X}_{4} \mathrm{X}_{1}$ & 0.036 & 0.023 \\
Lack of Fit & 0.058 & 0.057 \\
$\mathrm{r}^{2}$ & 0,768 & 0,897 \\
$\mathrm{r}^{2}$-adj & 0,731 & 0,872 \\
\hline
\end{tabular}

AG: gallic acid.

AppliChem, Barcelona, Spain)) at a flow rate of $0.2 \mathrm{~mL} \mathrm{~min}^{-1}$ (injection volume of $90 \mu \mathrm{L}$ ). The gradient was linear from $0 \%$ to $40 \%$ B for $60 \mathrm{~min}$, followed by $100 \%$ B from 65 to $70 \mathrm{~min}$, and held with $100 \%$ B from 70 to $75 \mathrm{~min}$. The composition of the eluent was then restored to $100 \% \mathrm{~A}$ for $2 \mathrm{~min}$, and then the system was reequilibrated for $14 \mathrm{~min}$. The mass spectrometer was equipped with an electrospray interface (ESI), which was operated in positive-ion mode and controlled by the Xcalibur $^{\circledR}$ software (version 2.0). The parameters of the ESI source were as follows: positive-ion mode spray voltage of 4.0 $\mathrm{kV}$, capillary voltage of $49 \mathrm{~V}$, capillary temperature of $275^{\circ} \mathrm{C}$, and tube lens of $120 \mathrm{~V}$. The identification of the polyphenol compounds was based on their molecular weight, using the Phenol-Explorer database containing 502 polyphenols. Bixin was identified according to its molecular weight $(394.5 \mathrm{~g} / \mathrm{mol})$ $[10,18]$.

\section{Results and Discussion}

3.1. Experimental Design for Optimization of UAE. The experimental matrix was composed of 30 runs. The experiments were performed in triplicate and Table 1 lists the experimental conditions.

The ANOVA was used to evaluate the significance of the quadratic polynomial models. For each term in the models, a large F-value and a small $p$-value would imply a more significant effect on the respective response variable [19]. The ANOVA table for the UAE (Table 2), for both dependent variables, shows that most of the factors studied were statistically significant $(p<0.05)$ in their linear terms; $p$-value for bixin (\%) of $\mathrm{X}_{2}-\mathrm{pH}$ is 0.065 , which is also $>0.050$. $p$-value for polyphenol of $\mathrm{X}_{1}$-treatment tine and $\mathrm{X}_{3} \mathrm{X}_{4}$ is $>0.050$, too.

The statistical significance of the independent variables is attributed to the ionization states of the aliphatic molecules upon the modification of the $\mathrm{pH}$ and physical processes of mass transfer attributed to the effect of ultrasounds and solvent concentration. Bixin is a carotenoid having a highly 


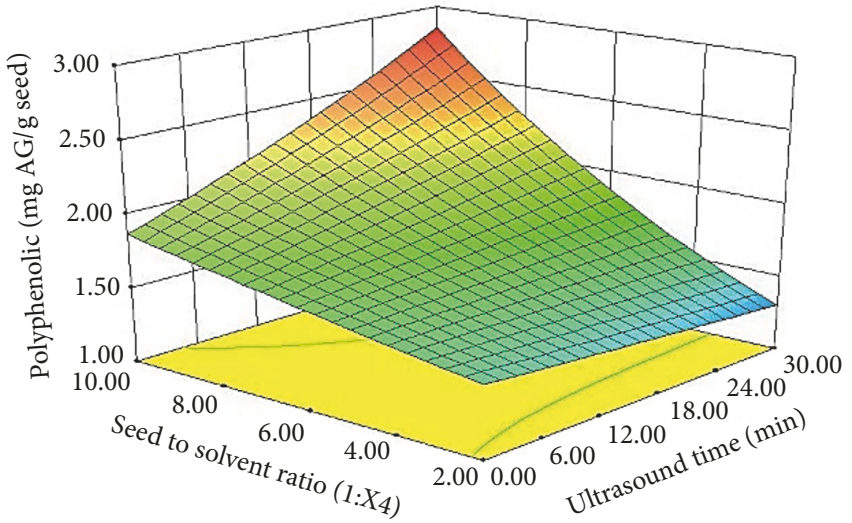

(a)

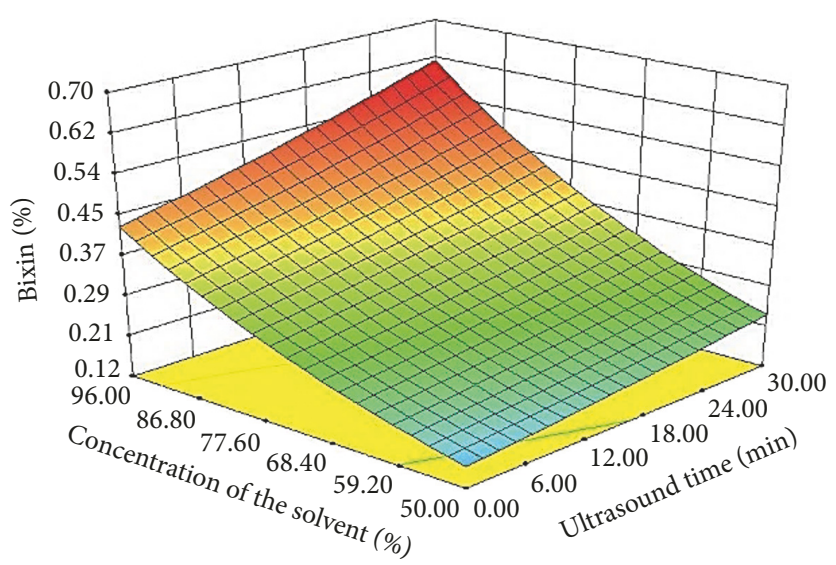

(b)

FIGURE 1: Response surface plots for the significant effects of seed-to-solvent ratio $v s$. treatment time and concentration of the solvent $v s$. treatment time for (a) polyphenol compounds and (b) bixin.

TABle 3: Predicted local maximum in the optimization of the UAE applying a Box-Behnken experimental design.

\begin{tabular}{|c|c|c|c|c|c|c|}
\hline Parameter & $\mathrm{pH}$ & $\begin{array}{c}\text { Solvent } \\
\text { concentration of } \\
\text { the }(\%)\end{array}$ & $\begin{array}{l}\text { Seed-to-solvent } \\
\text { ratio }(1: \mathrm{X} 4)\end{array}$ & Treatment time (min) & $\begin{array}{c}\text { Polyphenol } \\
\text { content } \\
\text { (mg AG/g seed) }\end{array}$ & $\begin{array}{c}\text { Bixin } \\
(\%)\end{array}$ \\
\hline Predicted & 7.5 & 95.98 & 7.82 & 30.00 & 2.71 & 0.43 \\
\hline \multirow[t]{3}{*}{ Experimental } & 7.0 & 96.00 & 7.00 & 20.00 & 3.81 & 0.62 \\
\hline & & & Relative error & & -1.10 & -0.19 \\
\hline & & & Absolute error (\%) & & 40.74 & 44.42 \\
\hline
\end{tabular}

Values are expressed as mean \pm standard deviation $(n=3)$. AG: gallic acid.

conjugated structure and presents a carboxyl group. It is also highly soluble at basic $\mathrm{pH}$. On the other hand, polyphenol compounds are slightly acidic molecules and their solubility is not significantly influenced by the medium $\mathrm{pH}$. Therefore, the concentration of the extraction solvent (i.e., ethanol) was the variable of greater statistical significance for all compounds. The statistical significance of seed-to-solvent ratio was attributed to the saturation of the extraction medium. Further, the significance of the treatment time in the extraction process was related to the residence time of the cavitation bubbles in contact with the seeds, easing the release of the metabolites. During the first 15 minutes of ultrasound treatment, mass transfer occurred mainly by convection and corresponded to the solubility of the extracted solute, then diffusion phenomena took place involving the internal part of the seed particles where the extraction of the compounds is maximized [20,21]. The response surfaces plots obtained from the polynomial models are shown in Figure 1. All the models were subjected to an optimization process. The polynomial equations for the response variables are described as follows:

$$
\begin{aligned}
\ln (\text { bixin })= & -5.61+0.03 * X_{2}+0.07 * X_{3} \\
& +0.46 X_{4}-0.01 * X_{1}-0.01 \\
& * X_{3} * X_{4}+0.01 * X_{4} * X_{1}
\end{aligned}
$$

$$
\begin{aligned}
\ln (\text { polyphenols })= & -0.17+0.01 * X_{3}+0.03 * X_{4} \\
& -0.01 * X_{1}+0.01 * X_{4} * X_{1}
\end{aligned}
$$

The plots describe how the application of ultrasounds accelerates the extraction process of both type of bioactive compounds. Once both treatments were optimized, the estimated conditions for the UAE, along with their relative error are listed in Table 3. The absolute bias of the UAE process was high, and thus the experimental results obtained were greater than those predicted by the statistical analysis.

Results from the UAE were compared with a previously reported microwave-assisted extraction (MAE) conduced on the same seeds [12]. The MAE is based on the exposure of the extract to high-energy electromagnetic waves generating heating of medium and in turn, increasing the energy transfer rate. The reported extraction yield of polyphenol compounds (mg AG/g seed) and bixin (\%) by MAE corresponds to 3.08 \pm 0.01 and $0.58 \pm 0.02$, respectively. These yields are close to those obtained reported in this study for UAE (Table 3 ). A detailed analysis of the MAE showed a treatment time (5 min), solvent concentration (ethanol) (96\%), and a solventto-seed ratio (5.95:1) as optimal. This means that a shorter treatment time is needed for MAE as compared to the UAE to get about the same yield [12]. Emine and collaborators obtained similar results when compared both extraction techniques for polyphenol compounds from nettle. In this 
TABLE 4: Minimum inhibitory concentration (MIC) at different pHs against B. cereus and S. aureus and antioxidant activity of the extracts obtained by UAE and leaching.

\begin{tabular}{|c|c|c|c|c|}
\hline \multicolumn{2}{|c|}{ Assay/extract } & UAE & Leaching & MAE \\
\hline \multirow{3}{*}{ Bacillus cereus } & $\mathrm{pH} 11(\mathrm{mg} / \mathrm{L})$ & $37^{\mathrm{a}}$ & $48^{\mathrm{b}}$ & $16^{\mathrm{c}}$ \\
\hline & $\mathrm{pH} 7$ (mg /L) & $37^{\mathrm{a}}$ & $48^{\mathrm{b}}$ & $16^{\mathrm{c}}$ \\
\hline & $\mathrm{pH} 4(\mathrm{mg} / \mathrm{L})$ & $37^{\mathrm{a}}$ & $48^{\mathrm{b}}$ & $16^{\mathrm{c}}$ \\
\hline \multirow{3}{*}{ Staphylococcus aureus } & pH 11 (mg /L) & $9^{a}$ & $48^{\mathrm{b}}$ & $8^{a}$ \\
\hline & $\mathrm{pH} 7(\mathrm{mg} / \mathrm{L})$ & $9^{a}$ & $48^{\mathrm{b}}$ & $8^{\mathrm{a}}$ \\
\hline & $\mathrm{pH} 4(\mathrm{mg} / \mathrm{L})$ & $9^{a}$ & $48^{\mathrm{b}}$ & $8^{\mathrm{a}}$ \\
\hline Bixin & $(\%)$ & $0.621^{\mathrm{a}} \pm 0.031$ & $0.165^{\mathrm{b}} \pm 0.002$ & $0.576^{\mathrm{a}} \pm 0.015$ \\
\hline Polyphenols & mg AG/g seed & $3.814^{\mathrm{a}} \pm 0.201$ & $0.343^{\mathrm{b}} \pm 0.003$ & $3.078^{\mathrm{a}} \pm 0.012$ \\
\hline ABTS & $\mu \mathrm{M}$ Trolox/L extract & $1035.652^{\mathrm{a}} \pm 189.517$ & $174.782^{\mathrm{b}} \pm 8.700$ & $577.68^{c} \pm 5$ \\
\hline FRAP & $\mu \mathrm{M}$ Trolox/L extract & $424.700^{\mathrm{a}} \pm 7.000$ & $127.033^{\mathrm{b}} \pm 2.517$ & $316.37^{\mathrm{c}} \pm 10$ \\
\hline DPPH & $\mu \mathrm{M}$ Trolox/L extract & $1161.524^{\mathrm{a}} \pm 28.938$ & $811.048^{\mathrm{b}} \pm 5.774$ & $1043.90^{\mathrm{c}} \pm 50$ \\
\hline
\end{tabular}

Values are expressed as mean \pm standard deviation $(n=3)$. Different letters indicate statistically significant differences $(\mathrm{p}<0.05)$.

case, they used a treatment of $10 \mathrm{~min}$ at $407 \mathrm{~W}$ retrieving gallic acid (1.125 mg/g db), caffeic acid (1.223 mg/g db), chlorogenic acid (4.798 $\mathrm{mg} / \mathrm{g} \mathrm{db}), \mathrm{p}$-coumaric acid (1.157 $\mathrm{mg} / \mathrm{g} \mathrm{db}$ ), naringenin (5.582 $\mathrm{mg} / \mathrm{g} \mathrm{db}$ ), and naringin (0665 $\mathrm{mg} / \mathrm{g} \mathrm{db}$ ). These compounds were statistically comparable to those obtained by UAE conducted at $80 \%$ power and $30 \mathrm{~min}$ of treatment time $(1.209,1.289,4.453,1.100,5.735$, and $0.784 \mathrm{mg} / \mathrm{g} \mathrm{db}$, respectively). In annatto seeds MAE shows the same extraction efficiency in a shorter period of time [22]. The major difference between both techniques is focused on the diffusion resistance for the mass and heating transfer of bioactive compounds. Thus, the UAE generates microdomains and cavitations of the bubbles causing a greater temperature ramp, whereas the MAE changes the molecular rotation and ionic mobility of the medium generating heating in the whole system and not in form of microdomains.

\subsection{Effect of the UAE on the Antimicrobial and Antioxidant} Activities of the Extract. The antioxidant and antimicrobial properties of the extracts obtained at the optimal operational conditions for the UAE were compared with an extract obtained by conventional extraction and a previous study conducted by MAE. Table 4 shows a larger antimicrobial and antioxidant activities for the UAE and MAE than that observed for the extract obtained by convectional extraction. This is explained by the higher content of polyphenol and bixin compounds present in both emerging extraction methods.

The extract of the seeds of annatto contains mainly bixin and polyphenol compounds which are responsible for the antioxidant and antimicrobial activities [2]. Particularly, bixin is a highly conjugated molecule and polyphenol compounds present hydroxyl groups in its structure having the ability to capture electrons, extinguishing the singlet oxygen, deactivating the excited triplet state of sensitizers which are usually associated with photosensitization and sweeping free radicals during their transition states. As a result, these compounds showed a large antioxidant activity. On the other hand, the antimicrobial activity is attributed mainly to the content of polyphenol compounds in the extract. These compounds have the ability to denature the proteins of microbial cell membranes and thus generate their inactivation or death, without being affected by the medium $\mathrm{pH}$ [2]. Consequently, the antimicrobial and antioxidant activities increased in the extracts obtained by UAE and MAE due to the greater amount of bioactive compounds in comparison to the extract obtained by leaching. Similar results were obtained by Zhang et al. (2010) and Yolmeh et al. (2014) when UAE was used for the extraction of astaxanthin and bixin respectively, showing an increased antioxidant capacity $[3,23]$.

\subsection{Identification of Bixin and Polyphenol Compounds of} the Extract Obtained by UAE under Optimal Conditions. The extract obtained by UAE was subjected to an LC/ESIMS using an orbitrap as an MS analyzer for the identification bioactive compounds [2]. The monoisotopic mass was searched in a database of plant phenolic compounds and the results were listed in Figure 2. Seven polyphenol compounds were identified, including catechin (flavonoids-flavanols), chlorogenic acid or 5-caffeoylquinic acid (phenolic acidshydroxycinnamic acids), chrysin (flavonoids-flavanols), butein (flavonoids-chalcone), hypolaetin (flavonoids-flavanols), licochalcone A (flavonoids-chalcone), xanthohumol (flavonoids-chalcone). Furthermore, compounds such as hypolaetin and chlorogenic acid or 5-Caffeoylquinic acid were previously identified by Campos et al. (2011) who designed a chromatographic method for the quantification of bixin and polyphenol compounds from the extract of annatto seeds. They reported exclusively bixin as the main carotenoid compound accounting for the $80 \%$ in the annatto seed extracts. Further, they also reported hypolaetin and caffeic acid derivatives as the main polyphenol compounds. However, they did not identify any other type of polyphenols in the extract $[1,10]$.

Despite the verified antioxidant activity of the compounds extracted from annatto seeds and identified by the orbitrap, some of them, particularly, catechin, chlorogenic acid, chrysin, and licochalcone $\mathrm{A}$, present antimicrobial activity against gram (+), gram (-) bacteria, and 


\begin{tabular}{lccccc}
\hline Compound & M.F. & M.F. (adduct $\mathrm{H})$ & M.W. & M.W. (adduct $\mathrm{H})$ & $\mathrm{T}_{\mathrm{R}}(\mathrm{min})$ \\
\hline Bixin & $\mathrm{C}_{25} \mathrm{H}_{30} \mathrm{O}_{4}$ & $\mathrm{C}_{25} \mathrm{H}_{31} \mathrm{O}_{4}$ & 394.22169 & 395.22169 & 73.3 \\
Catechin & $\mathrm{C}_{15} \mathrm{H}_{14} \mathrm{O}_{6}$ & $\mathrm{C}_{15} \mathrm{H}_{15} \mathrm{O}_{6}$ & 290.07903 & 291.08631 & 15.9 \\
Chlorogenic acid & $\mathrm{C}_{16} \mathrm{H}_{18} \mathrm{O}_{9}$ & $\mathrm{C}_{16} \mathrm{H}_{19} \mathrm{O}_{9}$ & 354.10236 & 355.10236 & 73.6 \\
Chrysin & $\mathrm{C}_{15} \mathrm{H}_{10} \mathrm{O}_{4}$ & $\mathrm{C}_{15} \mathrm{H}_{11} \mathrm{O}_{4}$ & 254.06519 & 255.06519 & 70.2 \\
Butein & $\mathrm{C}_{15} \mathrm{H}_{12} \mathrm{O}_{5}$ & $\mathrm{C}_{15} \mathrm{H}_{13} \mathrm{O}_{5}$ & 272.07575 & 273.07575 & 72.6 \\
Hipolaetin & $\mathrm{C}_{15} \mathrm{H}_{10} \mathrm{O}_{7}$ & $\mathrm{C}_{15} \mathrm{H}_{11} \mathrm{O}_{7}$ & 302.04993 & 303.04993 & 77.2 \\
Licochalcone A & $\mathrm{C}_{21} \mathrm{H}_{22} \mathrm{O}_{4}$ & $\mathrm{C}_{21} \mathrm{H}_{23} \mathrm{O}_{4}$ & 338.15909 & 339.15909 & 65.4 \\
Xanthoangelol & $\mathrm{C}_{25} \mathrm{H}_{28} \mathrm{O}_{4}$ & $\mathrm{C}_{25} \mathrm{H}_{29} \mathrm{O}_{5}$ & 392.20604 & 393.20604 & 77.2 \\
\hline
\end{tabular}

M.F.: molecular formula; M.W. molecular weight; TR: retention time

(a)

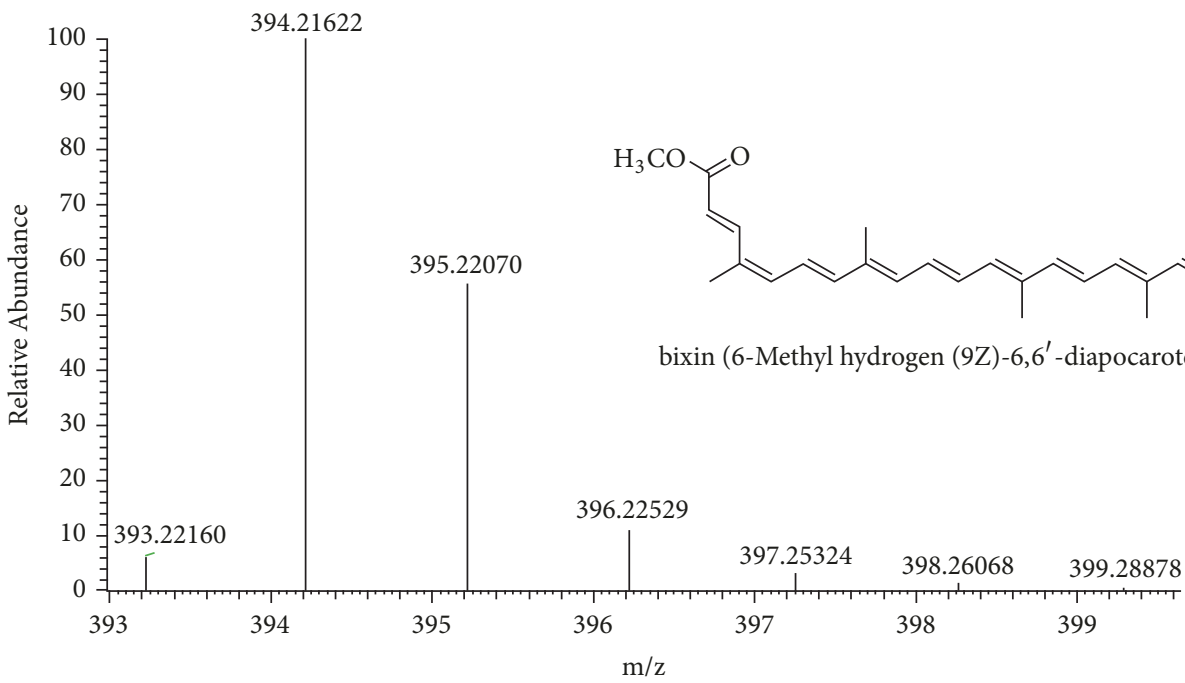

(b)

Peak spectrum for bixin<smiles>Oc1cc(O)c2c(c1)O[C@H](c1ccc(O)c(O)c1)C(O)Cc1c(O)cc(O)c(O)c1-2</smiles>

Hypolaetin<smiles>O=C(O)C1(O)CC(O)C(O)C(OC(O)CCc2ccc(O)c(O)c2)C1</smiles>

Chlorogenic acid<smiles>C=CC(C)(C)c1cc(/C=C/C(=O)c2ccc(O)cc2)c(O)cc1O</smiles>

Licochalcone<smiles>O=c1cc(-c2ccccc2)oc2cc(O)cc(O)c12</smiles>

Chrysin<smiles>O=C(/C=C/c1ccc(O)c(O)c1)c1ccc(O)cc1O</smiles>

Butein

(c)

FIGURE 2: (a) Bioactive compounds identified in annatto seeds extract by LC/ESI-MS analysis. (b) Experimental MS2 spectrum of the ion at $\mathrm{m} / \mathrm{z} 394.22169$ with the predicted structures of the ion at $\mathrm{m} / \mathrm{z} 395.22070$ arising from bixin (6-Methyl hydrogen (9Z)-6,6 ${ }^{\prime}$-diapocarotene-6). (c) Structures of polyphenol compounds identified from the annatto seeds extract.

fungi [24-27]. Further, Dzotam and collaborators in 2017 reported the antimicrobial activity of six Cameroonians food plants (Psidium guajava, Persea americana, Citrus sinensis, Coula edulis, Mangifera indica, and Camellia sinensis) against enteric multiresistant bacteria (Providencia stuartii, Klebsiella pneumoniae, and Escherichia coli). They declared that the antimicrobial activity is partly attributed to polyphenol compounds such as catechin. This compound either affects 
the membrane fluidity in the hydrophilic and hydrophobic regions of lipid bilayers of the microorganism, or inhibits the action of DNA polymerases [24]. Further, chlorogenic acid, chrysin, and licochalcone A have also been reported as polyphenol compounds with antimicrobial activity against $E$. coli, M. Luteus, and S. aureus. The latter is more susceptible due to differences of the proteins of the cell wall. For instance, the cell wall of E. coli contains of a thin layer of peptidoglycans and an external layer of lipoproteins, lipopolysaccharides, and phospholipids, whereas the cell wall of $\mathrm{S}$. aureus includes a peptidoglycan layer with many pores. The porous structure of the cell wall of $S$. aureus makes it easy for interaction with chlorogenic acid or other antimicrobial compounds, inhibiting the synthesis of nucleic acids, the function of the cytoplasmic membrane, or the energetic metabolism [25-27].

\section{Conclusions}

The UAE technique accelerated the extraction process, reduced energy expenditure, and increased the yield of the bioactive compounds present in the annatto seeds. The UAE preserved the metabolites with a greater efficiency and thus favored their functional activities. In addition, the presence of bixin and seven polyphenol compounds such as catechin, chlorogenic acid, chrysin, butein, hypolaetin, licochalcone A, and xanthohumol found in the extract was responsible for their antimicrobial and antioxidant activities.

\section{Data Availability}

The data used to support the findings of this study are available from the corresponding author upon request.

\section{Conflicts of Interest}

The authors declare that there are no conflicts of interest regarding the publication of this paper

\section{Acknowledgments}

This work was sponsored by Colciencias through the grant 727 of 2015 for the formation of Colombian PhDs and 715 for research and development projects in engineering-2015. The authors also thank the sustainability strategy 2018-2019 of the University of Antioquia.

\section{References}

[1] R. C. Chisté, F. Yamashita, F. C. Gozzo, and A. Z. Mercadante, "Simultaneous extraction and analysis by high performance liquid chromatography coupled to diode array and mass spectrometric detectors of bixin and phenolic compounds from annatto seeds," Journal of Chromatography A, vol. 1218, no. 1, pp. 57-63, 2011.

[2] M. Viuda-Martos, G. L. Ciro-Gómez, Y. Ruiz-Navajas et al., "In vitro antioxidant and antibacterial activities of extracts from annatto (Bixa orellana L.) leaves and seeds," Journal of Food Safety, vol. 32, no. 4, pp. 399-406, 2012.
[3] M. Yolmeh, M. B. Habibi Najafi, and R. Farhoosh, "Optimisation of ultrasound-assisted extraction of natural pigment from annatto seeds by response surface methodology (RSM)," Food Chemistry, vol. 155, pp. 319-324, 2014.

[4] Z. Lianfu and L. Zelong, "Optimization and comparison of ultrasound/microwave assisted extraction (UMAE) and ultrasonic assisted extraction (UAE) of lycopene from tomatoes," Ultrasonics Sonochemistry, vol. 15, no. 5, pp. 731-737, 2008.

[5] S. C. Alcázar-Alay, J. F. Osorio-Tobón, T. Forster-Carneiro, and M. A. A. Meireles, "Obtaining bixin from semi-defatted annatto seeds by a mechanical method and solvent extraction: process integration and economic evaluation," Food Research International, vol. 99, pp. 393-402, 2017.

[6] T. Taham, D. O. Silva, and M. A. Barrozo, "Improvement of bixin extraction from annatto seeds using a screen-topped spouted bed," Separation and Purification Technology, vol. 158, pp. 313321, 2016.

[7] L. M. Rodrigues, S. C. Alcázar-Alay, A. J. Petenate, and M. A. Meireles, "Bixin extraction from defatted annatto seeds," Comptes Rendus Chimie, vol. 17, no. 3, pp. 268-283, 2014.

[8] K. Ghafoor, Y. H. Choi, J. Y. Jeon, and I. H. Jo, "Optimization of ultrasound-assisted extraction of phenolic compounds, antioxidants, and anthocyanins from grape (Vitis vinifera) seeds," Journal of Agricultural and Food Chemistry, vol. 57, no. 11, pp. 4988-4994, 2009.

[9] T. Zou, Q. Jia, H. Li, C. Wang, and H. Wu, "Response surface methodology for ultrasound-assisted extraction of astaxanthin from haematococcus pluvialis," Marine Drugs, vol. 11, no. 5, pp. 1644-1655, 2013.

[10] G. Aldini, L. Regazzoni, A. Pedretti et al., "An integrated high resolution mass spectrometric and informatics approach for the rapid identification of phenolics in plant extract," Journal of Chromatography A, vol. 1218, no. 20, pp. 2856-2864, 2011.

[11] M. Barbosa, C. Borsarelli, and A. Mercadante, "Light stability of spray-dried bixin encapsulated with different edible polysaccharide preparations," Food Research International, vol. 38, no. 8-9, pp. 989-994, 2005.

[12] J. Q. Quiroz, A. C. Torres, L. M. Ramirez, M. S. Garcia, G. C. Gomez, and J. Rojas, "Optimization of the microwave-assisted extraction process of bioactive compounds from annatto seeds (Bixa orellana L.)," Antioxidants, vol. 8, no. 2, article 37, 2019.

[13] T. Swain and W. E. Hillis, "The phenolic constituents of Prunus domestica. I.- the quantitative analysis of phenolic constituents," Journal of the Science of Food and Agriculture, vol. 10, no. 1, pp. 63-68, 1959.

[14] FAO/WHO, Rome, 1982.

[15] J. Contreras-Calderón, L. Calderón-Jaimes, E. Guerra-Hernández, and B. García-Villanova, "Antioxidant capacity, phenolic content and vitamin C in pulp, peel and seed from 24 exotic fruits from Colombia," Food Research International, vol. 44, no. 7, pp. 2047-2053, 2011.

[16] I. F. F. Benzie and J. J. Strain, "The ferric reducing ability of plasma (FRAP) as a measure of 'antioxidant power': the FRAP assay," Analytical Biochemistry, vol. 239, no. 1, pp. 70-76, 1996.

[17] H. H. Nurhuda, M. Y. Maskat, S. Mamot, J. Afiq, and A. Aminah, "Effect of blanching on enzyme and antioxidant activities of rambutan (nephelium lappaceum) peel," International Food Research Journal, vol. 20, no. 4, pp. 1725-1730, 2013.

[18] V. Neveu, J. Perez-Jimenez, F. Vos et al., "Phenol-explorer: an online comprehensive database on polyphenol contents in foods," Database, vol. 2010, pp. bap024-bap024, 2010. 
[19] L. Quanhong and F. Caili, "Application of response surface methodology for extraction optimization of germinant pumpkin seeds protein," Food Chemistry, vol. 92, no. 4, pp. 701-706, 2005.

[20] C. Da Porto, E. Porretto, and D. Decorti, "Comparison of ultrasound-assisted extraction with conventional extraction methods of oil and polyphenols from grape (Vitis vinifera L.) seeds," Ultrasonics Sonochemistry, vol. 20, no. 4, pp. 1076-1080, 2013.

[21] F. Rubio-Senent, J. Fernández-Bolaños, A. García-Borrego, A. Lama-Muñoz, and G. Rodríguez-Gutiérrez, "Influence of $\mathrm{pH}$ on the antioxidant phenols solubilised from hydrothermally treated olive oil by-product (alperujo)," Food Chemistry, vol. 219, pp. 339-345, 2017.

[22] A. E. Ince, S. Sahin, and G. Sumnu, "Comparison of microwave and ultrasound-assisted extraction techniques for leaching of phenolic compounds from nettle," Journal of Food Science and Technology, vol. 51, no. 10, pp. 2776-2782, 2014.

[23] L.-L. Zhang, M. Xu, Y.-M. Wang, D.-M. Wu, and J.-H. Chen, "Optimizing ultrasonic ellagic acid extraction conditions from infructescence of platycarya strobilacea using response surface methodology," Molecules, vol. 15, no. 11, pp. 7923-7932, 2010.

[24] J. K. Dzotam and V. Kuete, "Antibacterial and antibioticmodifying activity of methanol extracts from six cameroonian food plants against multidrug-resistant enteric bacteria," BioMed Research International, vol. 2017, Article ID 1583510, 19 pages, 2017.

[25] M. Zhao, H. Wang, B. Yang, and H. Tao, "Identification of cyclodextrin inclusion complex of chlorogenic acid and its antimicrobial activity," Food Chemistry, vol. 120, no. 4, pp. 1138$1142,2010$.

[26] A. Uzel, K. Sorkun, Ö. Önçağ, D. Çoğulu, Ö. Gençay, and B. Salih, "Chemical compositions and antimicrobial activities of four different Anatolian propolis samples," Microbiological Research, vol. 160, no. 2, pp. 189-195, 2005.

[27] T. P. Cushnie and A. J. Lamb, "Antimicrobial activity of flavonoids," International Journal of Antimicrobial Agents, vol. 26, no. 5, pp. 343-356, 2005. 


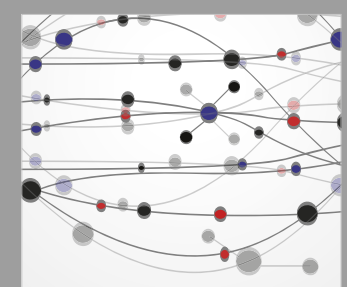

The Scientific World Journal
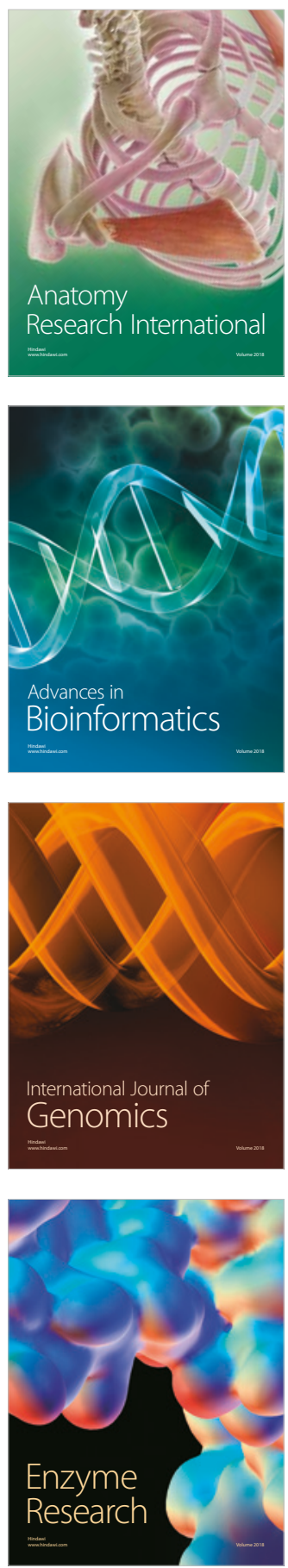
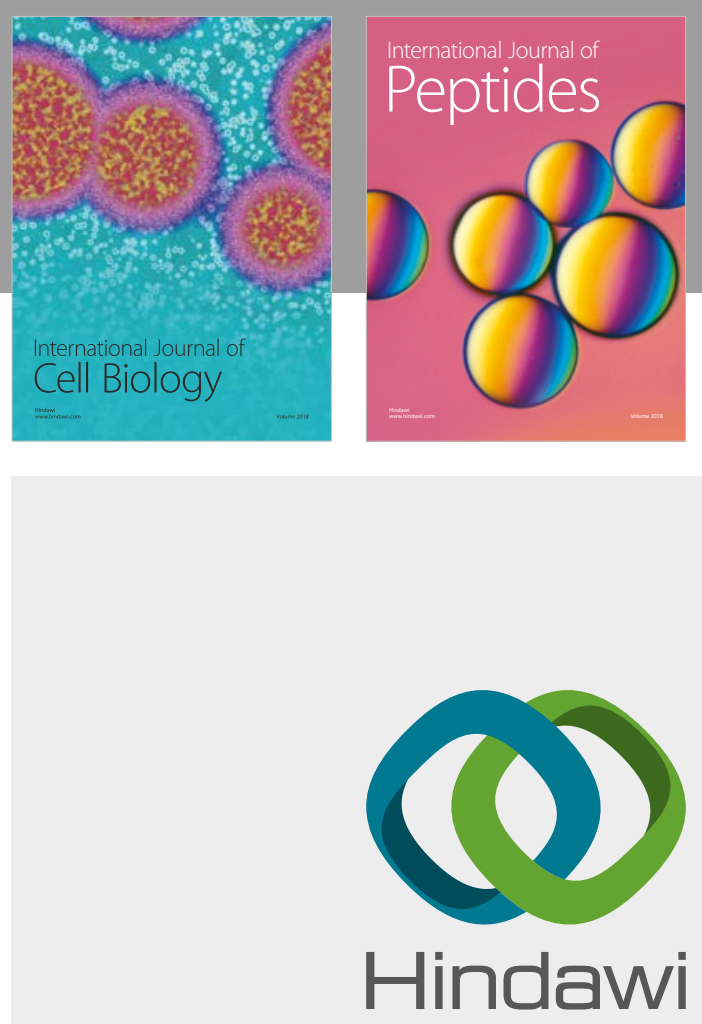

Submit your manuscripts at

www.hindawi.com
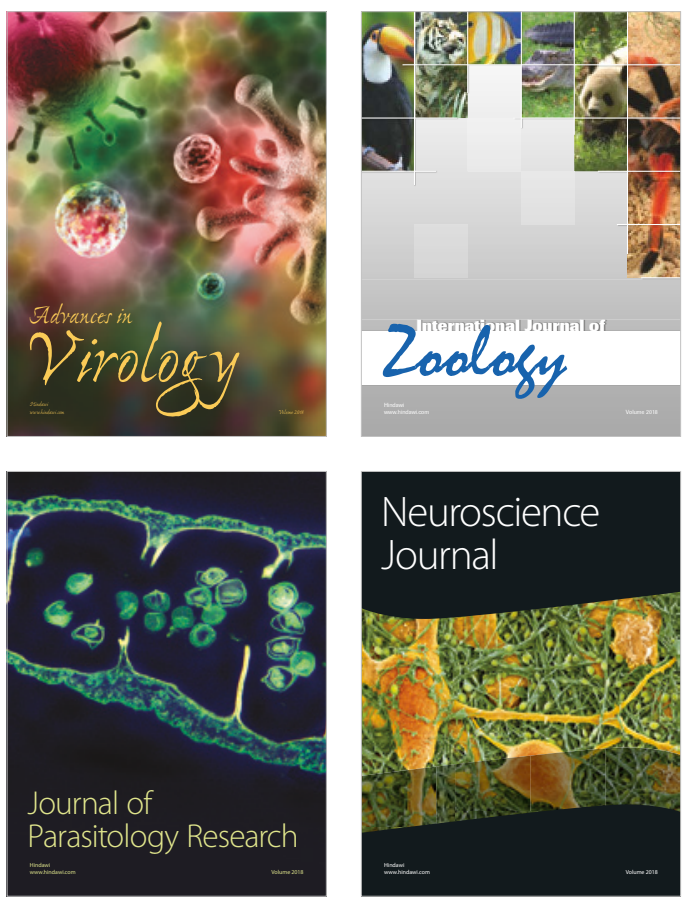
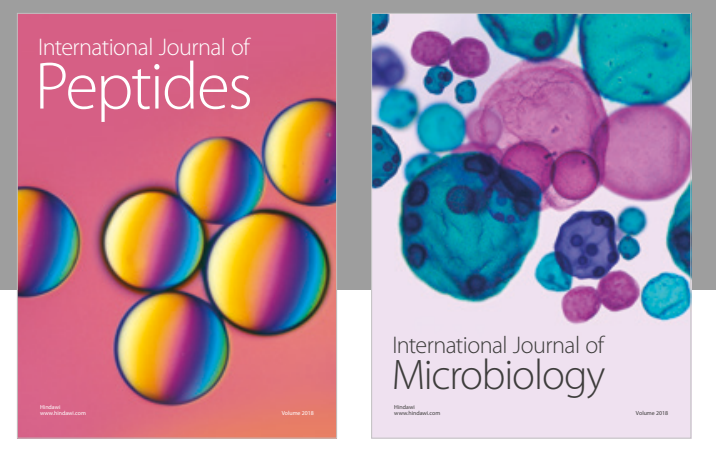

nternational Journal of Microbiology
Journal of
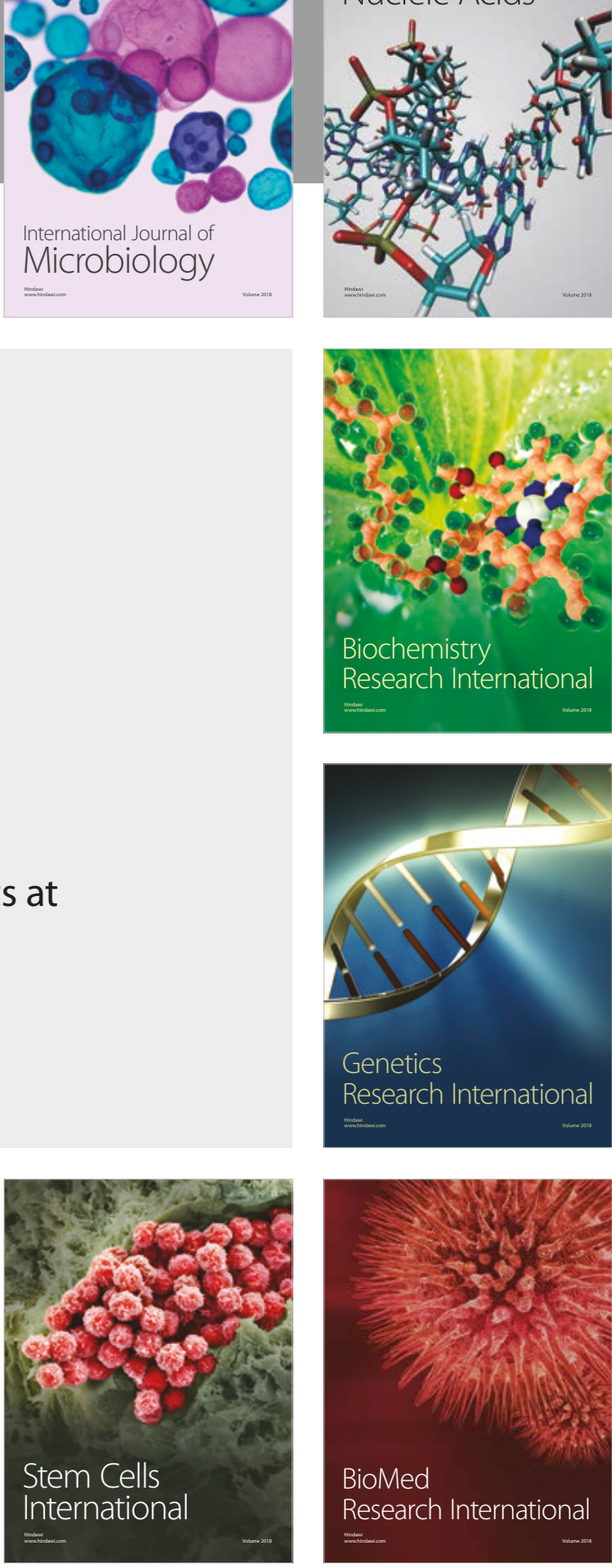
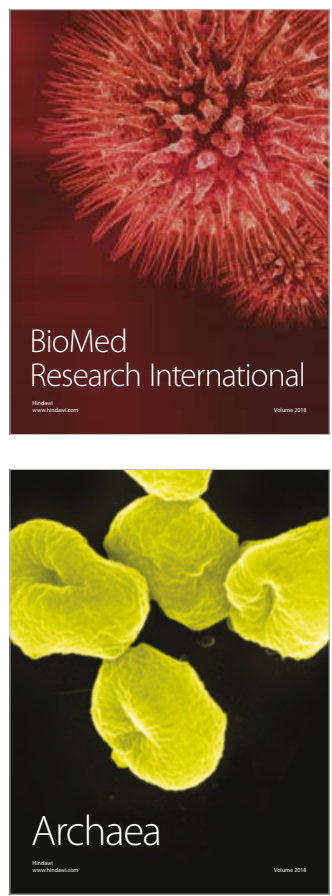